\title{
Prevalence of Staphylococcus aureus in Lactating Cows with Subclinical Mastitis and their Antibiogram in Organized Dairy Farm, Maharashtra, India
}

\author{
Mahendra Mohan Yadav* \\ Research cum Development Project on Cattle, Mahatma Phule Krishi Vidyapeeth, \\ Maharashtra State-413 722, India \\ *Corresponding author
}

\begin{abstract}
A B S T R A C T
The purpose of this study was to investigate sub-clinical mastitis in organized dairy farm and prevalence of Staphylococcus aureus with its antibiogram pattern. The present study

Keywords

Cattle, Sub clinical

mastitis,

Prevalence,

Organized dairy farm, Antibiogram

Article Info

Accepted:

28 February 2018

Available Online:

10 March 2018 was carried out at Research Cum Development Project on Cattle, Mahatma Phule Krishi Vidyapeeth, Rahuri, Maharashtra. A total of 1296 lactating crossbred cows (5184 quarters) were investigated for sub-clinical mastitis. Samples positive for sub-clinical mastitis were subjected for isolation and biochemical characterization. Isolates that was confirmed as $S$. aureus were subjected for antibiotic-susceptibility testing. The overall quarter wise incidence of sub clinical mastitis among 1296 crossbred cows was 3.62 per cent (188 quarters out of 5184 quarters). After biochemical characterization, S. aureus was confirmed in 152 samples $(80.85 \%)$. Antibiotic resistance pattern revealed that the highest resistance to the antimicrobials used was to observed in Cephalexin $(86.84 \%)$, followed by Co-trimoxazole $(82.89 \%)$, Penicillin G (82.23\%), Ampicillin (81.57\%), Cefoperazone (76.97\%), Ceftriaxone (69.73\%), Cefotaxime (65.13), Amoxyclav (63.15\%), and Tetracycline $(54.60 \%)$ Chloramphenicol (46.71\%), Ciprifloxacin (42.10\%), Gentamicin (38.81\%), Enrofloxacin and Levofloxacin (19.73\% each). This study confirms the importance of $S$. aureus as a major mastitis causing bacterium and existence of alarming level of resistance to frequently used antibiotic by $S$. aureus and a potential risk for human health from nearly possible transmission of the $S$. aureus strains as milk borne pathogen.
\end{abstract}

\section{Introduction}

In livestock (dairy) farming Mastitis continues to be one of the economically most important diseases. Especially bovine mastitis is one of important production diseases of dairy animals that affect the economy of farmers and thereby affecting the economy of Country. The severe economic losses in dairy cattle mastitis is due to reduced milk yield, treatment cost, labour cost, milk withheld following treatment and premature culling (Miller et al., 1993). Dua (2001) reported annual losses due to clinical and sub-clinical mastitis (SCM) to the tune of Rs 6053.21 crores in developing country like India.

The sub-clinical form of mastitis in dairy cows is important because this form is 15 to 40 times more prevalent than the clinical form, 
usually precedes the clinical form, long duration, difficult to detect, reduces milk production, and adversely affects milk quality (Seegers et al., 2003). The diagnosis of subclinical mastitis is more problematic since the milk appears normal but usually has an elevated somatic cell count. Early diagnosis of mastitis is vital because changes in the udder tissue take place much earlier than they become apparent.

One of the main etiological agents of subclinical mastitis is Staphylococcus aureus. It has been recognized as the most important cause of ruminant mastitis. As a remedy antimicrobials were used frequently as therapeutic purpose against $S$. aureus infection especially in mastitis cases. But the outcome is poor due to versatile nature of pathogen and multidrug resistance strains.

The aim of the present study was to investigate the incidence of sub-clinical mastitis cases in dairy cows and $S$. aureus in bovine sub-clinical mastitis cases and further to determine the antimicrobial resistance pattern of isolates.

\section{Materials and Methods}

\section{Animals}

The whole investigation was carried out on lactating dairy cows of Research cum Development Project (RCDP) on Cattle, Mahatma Phule Krishi Vidyapeeth (MPKV), Rahuri, Maharashtra State (India).

\section{Husbandry and management system}

Crossbred dairy cows used in this study were managed under loose housing system at RCDP on Cattle. All the cows were vaccinated twice in a year for Hemorrhagic Septicemia, Black Quarter and Foot and Mouth Disease. Twenty one days prior to vaccination deworming was carried out. They are provided with green grass and concentrate diet and are kept together in common shed but at peri-parturient period (advanced pregnancy and early lactating stage) they are maintained in separate byres. All cows were subjected to postmilking teat disinfection, those cows were dried off approximately two months before expected calving and all quarters of cows were infused with an antibiotic preparation approved for use in non-lactating cows following the last milking of lactation.

\section{Sampling}

A total of 108 lactating crossbred females were tested for sub-clinical mastitis per month i.e 1296 animals (5184 quarters) were tested for period of 1 year. Milk samples from each quarter were collected aseptically from apparently healthy lactating crossbred females. Teats were washed thoroughly and dried. The first three streams of milk from each teat were discarded. The teat end and orifice was sanitized with cotton swabs soaked in $70 \%$ ethanol.

\section{Sub clinical mastitis detection by California mastitis test}

California mastitis test (CMT) was carried out as described by Schalm et al., (1971). Briefly, from all the quarters $(\mathrm{N}=5184) 2 \mathrm{~mL}$ of milk samples was collected in each shallow cup in the CMT paddle. An equal amount of CMT reagent was added. The milk reagent mixture is swirled in a circular motion with presence of gel or slime being recorded for each quarter.

\section{Culture and identification of microorganisms}

The samples were inoculated on nutrient agar and blood agar at $37^{\circ} \mathrm{C}$ for 24 to 48 hours. Identification of isolates was done on basis of 
colony morphology, Grams' staining, catalase test, Oxidase test, Indole production, Citrate utilization, Methyl Red test, Voges Proskauer test (Cheesbrough, 1994). The colonies confirmed as Staphylococcus aureus were further tested for antimicrobial susceptibility.

\section{Antimicrobial susceptibility testing}

The antibiotic-susceptibility profile of isolates for 14 different antibiotics was prepared using the disk diffusion method on Mueller-Hinton agar as recommended by Clinical and Laboratory Standards Institute (2008). In brief, $S$. aureus isolates were grown overnight on blood agar at $37^{\circ} \mathrm{C}$, and the colonies were suspended in sterile saline water equivalent to a 0.5 McFarland standard.

The suspension $(100 \mu \mathrm{l})$ was spread over the medium plate. Then, the antibiotic disk was transferred aseptically on to the surface of the inoculated medium, and was incubated further at antibiotics at $37^{\circ} \mathrm{C}$, for a period of $24 \mathrm{~h}$. The antibiotics and their concentrations used are as follows: Ampicillin $(25 \mu \mathrm{g})$, Amoxyclav (30 $\mu \mathrm{g})$, Cefoperazone $(75 \mu \mathrm{g})$, Ceftriaxone (30 $\mu \mathrm{g})$, Cefotaxime $(10 \mu \mathrm{g})$, Cephalexin $(30 \mu \mathrm{g})$, Chloramphenicol $(30 \mu \mathrm{g})$, Ciprofloxacin (30 $\mu \mathrm{g})$, Co-Trimoxazole $(30 \mu \mathrm{g})$, Enrofloxacin $(10 \mu \mathrm{g})$, Gentamicin $(20 \mu \mathrm{g})$, Levofloxacin (5 $\mu \mathrm{g})$, Penicillin G (10 units) and Tetracycline (30 $\mu \mathrm{g})$.

\section{Results and Discussion}

The present study was conducted to investigate the quarter wise incidence of sub clinical mastitis in crossbreds of bovine and $S$. aureus in Sub-clinical mastitis cases at Research cum Development Project on Cattle, Mahatma Phule Krishi Vidyapeeth, Rahuri (India). The overall quarter wise incidence of sub clinical mastitis among 1296 apparently healthy crossbred cows was 3.62 per cent (188 quarters out of 5184 quarters) whereas 62 quarters $(1.19 \%)$ were found positive for Clinical mastitis and normal quarters were $4825(93.07 \%)$. Out of 188 quarters positive for sub-clinical mastitis, single quarter involvement per cow is seen in 166 cows $(88.30 \%)$, whereas 11 cows $(11.70 \%)$ showed sub-clinical mastitis in two quarters.

As compare to clinical mastitis $(1.19 \%)$, the incidence of subclinical mastitis $(3.62 \%)$ is nearly 3 times. From the total of 188 milk samples from cows with sub-clinical mastitis, 172 samples showed growth of aerobic bacteria. From 8 milk samples no growth was observed.

The $152 \mathrm{~S}$. aureus isolates were tested for antimicrobial susceptibility. The sensitivity and resistance of isolates to antibiotics is shown in Table 1. The highest resistance to the antimicrobials used was to observed in Cephalexin $(86.84 \%)$, followed by Cotrimoxazole $(82.89 \%)$, Penicillin G $(82.23 \%)$, Ampicillin (81.57\%), Cefoperazone (76.97\%), Ceftriaxone (69.73\%), Cefotaxime (65.13), Amoxyclav (63.15\%), and Tetracycline (54.60 $\%)$.

For successful breeding from the health and economic point of view, it is paramount importance that the udder of lactating animals should remain healthy.

The overall quarter wise prevalence of sub clinical mastitis was 3.62 per cent whereas 1.19 per cent was found positive for Clinical mastitis and normal healthy quarters were 93.07 per cent. Out of 188 quarters positive for sub-clinical mastitis, single quarter involvement per cow is seen in 88.30 per cent, whereas 11.7 per cent showed sub-clinical mastitis in two quarters. In contrast to present study, several reports (de Medeiros et al., 2009; Hussein, 2012) of very high quarter wise prevalence of subclinical mastitis were recorded. Higher prevalence rate $(36.36 \%$ and 
$21.7 \%$ ) was also reported by Islam et al., (2011) and Mdegela et al., (2009), respectively. These differences in the prevalence of subclinical mastitis are perhaps due to difference in managemental and hygienic practices adopted in different dairy herds. The low prevalence $(3.62 \%)$ in this study is due to extensive management practices followed at this farm including use of teat dip antiseptic solutions before and after milking of lactating cows, proper washing of milkers' hands, milking parlor using disinfectants, separate milking parlor etc.

As compare to clinical mastitis $(1.19 \%)$, the prevalence of subclinical mastitis $(3.62 \%)$ is nearly 3 times. Thus losses due to subclinical mastitis are more as compare to clinical mastitis. It also reflects that subclinical mastitis is responsible for 60-70 per cent of total economic losses associates with total mastitis infections. Moreover, subclinical mastitis frequently goes unnoticed and it is also impairing milk productions and reduced reproductive performance and increases culling of lactating animals.
From the total of 188 milk samples from cows with sub-clinical mastitis, 172 samples showed growth of aerobic bacteria. Failure to detect pathogens in 8 milk samples may be due to intermittent excretion of the organisms or their disappearance because of spontaneous recovery. Also the possibility of mycoplasmal mastitis cannot be ruled out in such cases, since the organism cannot be cultivated on common bacteriological media. After biochemical characterization, Staphylococcus aureus was confirmed in 152 samples $(80.85$ $\%$ ). A high percentage of subclinical mastitis milk samples were positive for $S$. aureus. Similar, reports was also recorded by Singh $e t$ al., (1982), Shukla et al., (1998), Patel et al., (2000) and Hussein (2012).

The higher infection rate of $S$. aureus is due to its ubiquitous nature and its ability to colonize the skin as well as the udder.

These organisms spread from animal to animal during milking. This organism is capable of causing peracute, acute, chronic, gangreneous and subclinical mastitis.

Table.1 Antibiogram results for S. aureus isolated from sub-clinical mastitis milk

\begin{tabular}{|c|c|c|c|c|c|c|}
\hline \multirow{2}{*}{$\begin{array}{l}\text { Sr. } \\
\text { No. }\end{array}$} & \multirow[t]{2}{*}{ Antibiotics } & \multicolumn{2}{|c|}{ Sensitive } & \multicolumn{2}{|c|}{ Resistant } & \multirow[t]{2}{*}{ Total } \\
\hline & & No. & $\%$ & No. & $\%$ & \\
\hline 1 & Ampicillin & 28 & 18.43 & 124 & 81.57 & 152 \\
\hline 2 & Amoxyclav & 56 & 36.85 & 96 & 63.15 & 152 \\
\hline 3 & Cefoperazone & 35 & 23.03 & 117 & 76.97 & 152 \\
\hline 4 & Cefotaxime & 53 & 34.87 & 99 & 65.13 & 152 \\
\hline 5 & Ceftriaxone & 46 & 30.27 & 106 & 69.73 & 152 \\
\hline 6 & Cephalexin & 20 & 13.16 & 132 & 86.84 & 152 \\
\hline 7 & Chloramphenicol & 81 & 53.29 & 71 & 46.71 & 152 \\
\hline 8 & Ciprofloxacin & 88 & 57.90 & 64 & 42.10 & 152 \\
\hline 9 & Co-Trimoxazole & 26 & 17.11 & 126 & 82.89 & 152 \\
\hline 10 & Enrofloxacin & 122 & 80.27 & 30 & 19.73 & 152 \\
\hline 11 & Gentamicin & 93 & 61.19 & 59 & 38.81 & 152 \\
\hline 12 & Levofloxacin & 122 & 80.27 & 30 & 19.73 & 152 \\
\hline 13 & Penicillin $\mathrm{G}$ & 27 & 17.77 & 125 & 82.23 & 152 \\
\hline 14 & Tetracycline & 69 & 45.40 & 83 & 54.60 & 152 \\
\hline
\end{tabular}


From the Table 1, it is observed that the higher resistance of $S$. aureus to various anitmicrobials agents like Ampicillin, Amoxyclav, Co-trimoxazole, Cephalexin, Cefoperazone, Ceftriaxone, Cefotaxime, Penicillin $G$ and Tetracycline. Similar findings was also reported by various authors (Miller et al., 1993; Mubarack et al., 2012; Nthawat et al., 2013; Patel et al., 2000; Pavulraj et al., 2013).

The moderate resistance to the antimicrobials used was noticed in Chloramphenicol (46.71\%), followed by Ciprifloxacin $(42.10 \%)$ and Gentamicin (38.81\%). Lower resistance was observed in Enrofloxacin and Levofloxacin (19.73\% each). Relatively moderate to low resistance of $S$. aureus was reported to Chloramphenicol, Ciprofloxacin, Enrofloxacin, Gentamicin, Levofloxacin was reported by Abera et al., (2013); Adwan, (2006); Awandkar et al., (2013); Nthawat et al., (2013). Our results are in agreement to these reports.

Higher resistance to ampicillin, amoxyclav and penicillin $\mathrm{G}$ is due to production of beta lactamase enzyme by isolates.

Resistance (24.95\%) to cefoperazone antibiotic is reported by Ikiz et al., (2013), who also reported higher sensitivity $(91.66 \%)$ to Gentamicin, which is in contrast to our findings of low sensitivity (61.19\%). Highest sensitivity of Staphylococcus aureus isolates to Gentamicin and Ampicillin was reported by Mubarack et al., (2012) and Pavulraj et al., (2013). Resistance to cefoperazone antibiotic is unusual as this antibiotic is recently introduced in Veterinary medicine in this area. But high resistance to all the cephalosporins may be attributed to its indiscriminate use in therapeutics in animals and human, irrespective of the infection may not be of bacterial origin. In contrast to present findings, Sharma et al., (2012) reported 100 per cent sensitivity of Staphylococcus aureus isolates to Ceftriaxone, Cefoperazone and Tetraacycline and high (90.90 to $100.0 \%)$ sensitivity towards Enrofloxacin, Cephalexin). Difference in findings towards newer and older antibiotics may be due to rationale use of these antibiotics at the farms under study of latter.

Antibiotic resistant strains of $S$. aureus of animal origin are posing a growing, worldwide, especially in developing countries like India. The effectiveness of current treatment regime for mastitis control in animals may become hazardous not only to animals but also to human health. The indiscriminate and injudicious administration of antibiotics / antimicrobials and irrational treatment of bovine mastitis with different antibiotics have invited severe complications like multiple drug resistance (Ganguly et al., 2016). Although innovations in various therapeutic regimens and improved management practices, mastitis unfortunately has remained ever green disease to Dairy industry (Mahapatra et al., 2018).

\section{Impacts}

The present investigation demonstrates the presence of $S$. aureus in high percentage in subclinically positive mastitis milk samples.

The existence of alarming level of resistance to frequently used antibiotic by $S$. aureus isolates in the farm.

It is therefore, very important to implement a systemic application of in vitro antibiotic susceptibility testing prior to the use of the antibiotics in both treatment and prevention of intra-mammary infections.

Antimicrobial resistant pathogens in animals have been incriminated as a potential risk for 
human health from nearly possible transmission of the $S$. aureus strains as milk borne pathogen.

\section{Acknowledgments}

The author is very much grateful to the Director of Research, Mahatma Phule Krishi Vidyapeeth, Rahuri, Maharashtra, India for providing the facilities for conducting this research.

\section{References}

Abera, M., Demie, B., Aragaw, K., Regassa, F. and Regassa, A. (2010). Isolation and identification of Staphylococcus aureus from bovine mastitic milk and their drug resistance patterns in Adama town, Ethiopia. African Journal of Dairy Farming and Milk Production. 1 (2): 19 23.

Abera, M., Demie, B., Aragaw, K., Regassa, F. and Regassa, A. (2013). Isolation and identification of Staphylococcus aureus from bovine mastitic milk and their drug resistance patterns in Adama town, Ethiopia. Journal of Veterinary Medicine and Animal Health. 2 (3): 29 - 34.

Adwan, G. M. (2006). Antibiotic resistance against Staphylococcal isolates recovered from subclinical mastitis in the north of Palestine. 14 (1): 1-9.

Awandkar, S. P., Bhikane, A. U. and Kulkarni, M. B. (2013). Antibiotic Resistance Trends in Clinical Bovine Mastitis. Biolife. 1 (3): 139-143.

Chavan, V. V., Digraskar, S. U., Dhonde, S. N. and Hase, P. B. (2007). Observation on bubaline subclinical mastitis in and around Parbhani, Indian Journal of Field Veterinarian. 3: 50.

Cheesbrough, M. (1994). Medical Laboratory Manual for Tropical Countries, $1^{\text {st }}$ edn., Vol. II, Butterworth-Heinemann, Oxford.

Clinical and Laboratory Standards Institute. (2008). Performance standards for antimicrobial disk and dilution susceptibility tests for bacteria isolated from animals.

De Medeiros, E. S., França, C. A., Carina, da C. Krewer., Renata, de M. Peixoto., Aldo, F. de Souza, Júnior., Marielly, B. Cavalcante., Mateus, M. da Costa and Rinaldo, A. Mota. (2011). Antimicrobial resistance of Staphylococcus spp. isolates from cases of mastitis in buffalo in Brazil. Journal of Veterinary Diagnosis Investigation. 23: 793

Dua, K. (2001). Incidence, aetiology and estimated loss due to mastitis in India-An update. Indian Dairyman. 53: 41-48.

Ganguly, S., Padhy, A., Sahoo, S., Garg, S. L., Wakchaure, R., Praveen, P. K., Para, P. A., Mahajan, T., Qadri, K., Sharma, R. (2016) Antibiogram of milk sample of a farm maintained dairy cow suffering from mastitis followed by its clinical recovery. Int. J. Sci. Environ. Technol., 5(1): 14851.

Hussein, S. A. (2012). Prevalence and bacterial etiology of subclinical mastitis in Dairy cows, in AI Sulaimaniyah District. Kufa Journal of Veterinary Medical Sciences. 3: 190-203.

Ikiz, S., Basaran, B., Bingol, E. B., Cetin, O., Kasikci, C., Ozgur, N. Y., Ucmak, M., Yilmaz, O., Gunduz, M. C. and Sabungu, A. (2013). Presence and antibiotic susceptibility patterns contagious mastitis agents (Staphylococcus aureus and Streptococcus agalactiae) isolated from milks of dairy cows with subclinical mastitis. Turkish Journal of Veterinary and Animal Science. 37: 569-574.

Islam, M. A., Islam, M. Z., Islam, M. A., Rahman, M. S. and Islam, M. T. (2011). Prevalence of subclinical mastitis in dairy cows in selected areas of Bangladesh. Bangladesh Journal of Veterinary Medicine. 9 (1): 73-78.

Mahapatra, A., Panigrahi, S., Patra, R.C., Rout, M. and Ganguly, S. (2018) A study on bovine mastitis related oxidative stress along with therapeutic regimen. Int. J. Curr. Microbiol. Appl. Sci., 7(1): xxxx- 
xxxx. doi: http://dx.doi.org/10.20546/ ijcmas.2018. 701. XXX. IN PRESS.

Mdegela, R. H., Ryoba, R., Karimuribo, E. D., Phiri, E. J., Løken, T., Reksen, O., Mtengeti, E., Urio, N. A. (2009). Prevalence of clinical and subclinical mastitis and quality of milk in smallholder dairy farms in Tanzania. Journal of the South African Veterinary Association. 80(3): 163-168.

Miller, G. Y., Barlet, P. C., Lance, S. E., Anderson, J. and Heider, L. E. (1993). Cost of clinical mastitis and mastitis prevention in dairy herds. Journal of American Veterinary Medical Association. 202: 1230-1236.

Mubarack, H. M., Doss, A., Vijayasanthi, M. and Venkataswamy, R. (2012). Antibiotic drug susceptibility of Staphylococcus aureus from subclinical mastitis in Coimbatore, Tamil Nadu, India. Veterinary World. 5 (6):352-355.

Nathawat, P., Bhati, T., Sharma, S. K., Mohammed, N., Kataria, A. K. (2013). Prevalence of Staphyloccous aurues in lactating goats with clinical mastitis and their antibiogram. ABAH Bioflux. 5(1): 32 - 37.

Patel, P. R., Raval, S. K., Rao, N., Mandali, G. C. and Jani, R. G. (2000). Status of mastitis in Gujarat State. Proceedings of the Round Table Conference of the Indian Association for the Advancement of Veterinary Research (IAAVR) on Mastitis, February 18-19, 2000, IVRi, Izatnagar, India, pp: 45-52.

Pavulraj, S., Amsaveni, S., Kalaisevi, L. and Ramesh, S. (2013). Screening of
Staphylococcus aureus isolates from mastitis for antibacterial susceptibility pattern and betalactamase production. Tamil Nadu Journal of Veterinary \& Animal Sciences. 9 (4): 300 - 307.

Saluja, P. S., Gupta, S. L., Kapur, M. P and Sharma, A. (2004). Prevalence of bovine mastitis in an organized dairy herd. Indian Veterinary Journal. 84: 1404-1405.

Sarvanan, P., Nagarajan, B. and Ramprabhu, R. (2000). A study on etiology, incidence and physical characters of milk in subclinical mastitis. Indian Veterinary Journal. 20: 76.

Schalm, O. W., Carroll, E. J. and Jain, N. C. (1971). Bovine mastitis. 1971 Edn. Lea and Febiger, Philadelphia, USA.

Seegers, H., Fourichon, C. and Beaudeau, F. (2003). Production effects related to mastitis and mastitis economics in dairy cattle herds. Veterinary Research. 34: 475491.

Sharma, P. A., Chabra, R and Sindhu, N. (2012). Prevalence of subclinical mastitis in cows: Its etiology and antibiogram. Indian Journal of Animal Research. 46 (4): 348-353.

Shukla SK, Dixit VP, Thapiyal DC and Kumar A. 1998. Bacteriological studies of mastitis in dairy cows. Indian Veterinary Medical Journal. 22: 261-264.

Singh, N., Sharma, V. K., Rajani, H. B. and Sinha, Y. R. (1982). Incidence, economy and test efficacy of subclinical mastitis in dairy animals. Indian Veterinary Journal. 59: 693-696.

\section{How to cite this article:}

Mahendra Mohan Yadav. 2018. Prevalence of Staphylococcus aureus in Lactating Cows with Subclinical Mastitis and their Antibiogram in Organized Dairy Farm, Maharashtra, India. Int.J.Curr.Microbiol.App.Sci. 7(03): 3674-3680. doi: https://doi.org/10.20546/ijcmas.2018.703.425 